\title{
Twenty Years after Folk Physics for Apes: Researchers' Understanding of How Nonhumans Understand the World
}

\author{
Jennifer Vonk
}

Department of Psychology, Oakland University

Corresponding author (Email: vonk@oakland.edu)

Citation - Vonk, J. (2020). Twenty years after folk physics for apes: Researchers' understanding of how nonhumans understand the world. Animal Behavior and Cognition, 7(3), 264-269. https://doi.org/10.26451/abc.07.03.01.2020

\begin{abstract}
Povinelli (2000) published a series of careful studies probing chimpanzees' understanding of physical causality in the book, "Folk Physics for Apes: The Chimpanzee's theory of how the world works." The studies and Povinelli's conclusions regarding chimpanzee cognition had a significant impact on the field of comparative cognition. One enduring lesson from 'Folk Physics' was the importance of shifting from a success-testing model to a focus on understanding the mechanisms underlying subjects' performance in research tasks. But have researchers fully embraced this lesson and has it translated to a better understanding of how other animals understand the world in the two decades that have followed? This special issue explores the evidence for causal understanding in a range of species, but it also reveals some changes in human understanding of nonhuman minds over the past 20 years.
\end{abstract}

Keywords - Folk physics, Causality, Tool use, Nonhumans, Researchers

The studies described in Povinelli's (2000) "Folk Physics for Apes: The Chimpanzee's theory of how the world works" have been highly cited and influential. They have inspired countless explorations of animal tool use in which researchers sought to provide evidence that at least some nonhumans were capable of understanding the functional properties of tools and their effects on other objects. What has happened in the twenty years since 'Folk Physics' (Povinelli, 2000) was published? Have researchers changed their perception of how chimpanzees and other animals view the world? Have researchers become more careful to avoid their own biases and expectations? At first glance, it might appear that researchers are more likely to attribute so-called "higher-order" cognitive processes to not just chimpanzees, but to several nonhuman species, including corvids and canids (Krupenye \& Call, 2019) compared to the evenly balanced debates that took place in the years immediately preceding and following the publication of Povinelli's influential book (e.g., Call, Hare \& Tomasello, 2003; Heyes, 1998; Povinelli \& Vonk, 2003). However, even if many comparative psychologists are increasingly willing to ascribe human-like causal reasoning capacities to some nonhumans, others are expressing some skepticism (e.g., Horschler et al., 2020; Taylor, 2020). At the very least, most researchers carefully consider alternative interpretations of their results, and ambiguous conclusions pointing to the need for further study appear more prominent in the literature (although see Farrar et al., 2020). Importantly, many comparative researchers have acknowledged the need to avoid top-down approaches to examining nonhuman cognition that are heavily biased by tests for well-known human cognitive processes (see de Waal \& Ferrari, 2010; Eaton et al., 2018).

Folk Physics was a strong influence on my own thinking as I was in the process of completing my dissertation on concept formation in orangutans and gorillas and had reached similar conclusions regarding the striking disconnect between the impressive ability of apes to reason about observable 
phenomena but the lack of evidence that they reason about constructs that are in principle unobservable (Vonk \& Povinelli, 2006, see Amodio et al., 2020, and Taylor, 2020, for similar conclusions regarding corvids). Like innumerable others, I had pursued the study of ape cognition with the goal of providing evidence that other apes are capable of reasoning in the abstract despite their lack of a symbolic language system. Although the apes in my own studies displayed impressive abilities in the very human-biased tasks I presented to them (e.g., Vonk, 2002, 2003, 2013; Vonk \& Hamilton, 2014; Vonk \& MacDonald, 2002, 2004), I was also developing a better appreciation for the many important and no less impressive differences between human and nonhuman minds. I felt very fortunate to join Povinelli's lab as a postdoctoral fellow and to work directly with the chimpanzees (and their trainers) that contributed countless data points to furthering our understanding of their understanding of the world. Those three years profoundly shaped my approach to science; particularly, the ironical need to think critically about the mechanisms underlying directly observable phenomena. My time with these amazing chimpanzees validated a sentiment I had held since childhood - that animals are interesting and valuable because of how they differ from humans.

When Povinelli embarked on his extensive studies of chimpanzee cognition - a small subset of which are covered in Folk Physics - he was similarly intrigued by the idea that chimpanzees may share important elements of human cognition. One of the unfortunate misconceptions of the work is that it failed to demonstrate the expected continuity between ape and human minds when, in actuality, the work succeeded in showing a great degree of overlap in the processes driving chimpanzee and human behavior. As Povinelli and colleagues have clearly articulated in numerous publications, many species share with humans the ability to draw inferences and predict outcomes based on observable connections between physical features and events. However, their careful research also revealed many significant differences. One key difference appears to be the inability to make inferences about unobservable causal forces (Vonk \& Povinelli, 2006). This lack of reasoning about causal forces (rather than predictive cues alone) may have also been exposed by the fact that chimpanzees did not appear to seek explanations for unexpected events (Povinelli \& Dunphy-Lelii, 2001) - an unexplored research question that will hopefully be invigorated by the commentary by Völter et al. (2020) in this special issue.

Some differences between the chimpanzees' expected and actual performance in the tests may well be accounted for by the artificiality of the laboratory setting and the objects presented to the chimpanzees - a topic that is emphatically pursued by Boesch (2020a, 2020b). It is undeniable that captivity is not the environment for which non-domesticated species have evolved. Nor does it provide the same rich experiences and choices available to their wild counterparts. It does however, provide some opportunites and affordances that are not available to wild animals. Because it is impossible to present analogous tasks and training experiences to captive and wild individuals, we may never know the extent to which captive animals are representative ambassadors for the cognitive capacities of their species. What laboratory studies can do is to expose a pattern of responding to tasks and challenges for which experimenters have a better idea of the individual's prior history and can directly control current conditions. But, as Povinelli and Henley (2020) point out in this issue, even in laboratory subjects, we must be careful not to assume that an animal enters a novel experimental task without any relevant experience. These issues are highlighted in Bernstein-Kurtycz and colleagues (2020) study of chimpanzee tool use. Concern over how an individual's history may impact its performance must move beyond assumptions about captive versus wild populations to carefully examine an individual's temperament, motivation, and attention. In the years since Folk Physics, researchers have become much more interested in individual differences (Vonk \& Povinelli, 2011) and the role that factors such as temperament and motivation play in influencing task performance (e.g., Shubiger et al., 2020; Vonk \& Eaton, 2018; Webster \& Rutz, 2020).

Another lasting lesson of Folk Physics came from Povinelli's exhaustive follow-up testing to uncover possible factors underlying the chimpanzees' successes and failures. Researchers often stop at a so-called 'positive' result and fail to probe whether the result reflects processes other than the cognitive trait that researchers aimed to provide evidence for. However, there is a growing recognition that results in either direction can emerge as a result of many competing factors or processes (Schubiger et al., 2020). 
Although there is an enduring tendency to focus on so-called 'positive' and 'negative' findings (see Farrar et al., 2020), it is less useful to dichotomize the outcomes of experiments in this way and more important to identify the processes underlying particular patterns of performance, regardless of how well they map on to known human processes. One of the positive recent changes in the field is the wider recognition that scientists should move beyond so-called "success testing" (Taylor, 2014) toward a more careful study of the mechanisms underlying both successes and failures in human conceived experimental tasks. Unfortunately, this shift has been slow to take hold of the field as a whole (de Waal \& Ferarri, 2010; Eaton et al., 2018). It is easy to understand, and even forgive, the resistance to moving away from anthropocentric tests because humans cannot view the world through any lens other than an anthropocentric one. However, some researchers have developed techniques that provide greater insight into what it must be like to be a honeybee, or a jumping spider, or a bird, and so on (Lazareva et al., 2012), that will hopefully allow researchers to begin their inqueries from a slightly less biased base. At the very least, researchers should shift their aim to understanding how an animal perceives a task and what features and strategies it attends to when solving challenges rather than assuming that success must be achieved via the same processes available to humans. Kersken and colleagues (2020) make an ambitious attempt to determine the type of representations formed by capuchin monkeys in an object individuation task, but like most of the reports in this issue, call out the need for further study to fully understand the developmental and evolutionary origins of object individuation.

Over time, there has been a softening of the presumed sharp divide between humans and all other species, even with regard to cognitive processes, with some notable exceptions (e.g., Penn et al., 2008). This softening should be accompanied by a recognition that the strong dichotomy between associative learning and cognition that is often represented in the literature is false (Vonk \& Edge, in press). Such a distinction has little utility for understanding species differences. So called 'higher-order' cognitive processes are better envisioned as an extension of the processes grounded in the formation of complex associations. Povinelli and colleagues have instead focused on distinguishing between "first order perceptually based cognitive processess" and "higher-order" cognitive processes (Penn et al., 2008). I will not attempt to improve upon Povinelli and Henley's (2020) clearly articulated explanation as to why no amount of controls will allow us to disentangle the contribution of these processes, but the message deserves emphasis as it has largely fallen on deaf ears (Povinelli et al., 2019). The tension between such explanations continues to muddy the conclusions from experimental tests presented in this issue, but researchers today are more inclined to acknowledge this challenge. For example, in this issue, researchers found that one elephant (Barrett \& Benson-Amram, 2020) and one orangutan (DeLong \& Burnett, 2020) could learn to use water as a tool to obtain a reward, but both sets of researchers conclude that the cognitive mechanisms underpinning this behavior elude their understanding. Amodio and colleagues (2020) found that Eurasian jays can use tools but fail to attend to functionally relevant features. Similarly, Jordan et al. (2020) were unable to determine whether new world monkeys solve a task by attending to functionally relevant features or other observable task features. Taylor (2020) reviews evidence for causal understanding in corvids in general and concludes that it is too early to determine whether corvids may be capable of reasoning about unobservables. Overall, the research in this issue confirms Povinelli's skepticism regarding the role that "higher-order, structural, role-based relational reasoning" (Penn et al., 2008; Povinelli et al., 2019) plays in performance in experimental tests of physical cognition. Furthermore, the construct of "causal reasoning" is underspecified and unlikely to fully capture the reasoning process that represents an understanding of the physical laws connecting events and objects.

In general, researchers are more cognizant of biases - both their own and those arising from the publication process - which is evidenced by a call for the publication of 'negative' results and preregistrations emphasizing methodological rigor over novel and exciting results (van 't Veer et al., 2016; Vonk \& Krause, 2018). In this issue, Farrar and colleagues (2020a) provide an example of how to empirically investigate possible publication and statistical biases specific to reports of physical cognition in nonhumans. Researchers have also taken to heart the concern that many results are not replicable, and this is particularly a problem when studying species that most researchers do not have access to (Vonk \& Povinelli, 2011). Recently, an explicit call for both greater collaboration (ManyPrimates, 2019a; 2019b) 
and replication (Beran, 2018, 2020; Farrar et al., 2020b; Stevens, 2017) has received a resoundingly positive response - indicating that researchers are actively working to overcome biases that have influenced research pursuits and publication biases in the past. This response will be reflected in a special issue on replication in comparative studies to appear in this journal in 2021.

One change that may assist in reducing the anthropocentric bias is the number and breadth of species that are studied today compared to the focus on nonhuman primates that dominated comparative cognition in the early part of this century. As Taylor (2020) notes in this issue, studies of corvid cognition were rather sparse in the years during which Povinelli conducted his extensive studies on tool use in chimpanzees. However, the study of corvids and canids have been two of the fastest growing areas of comparative cognition in the last two decades, accompanied by a general movement toward inclusion of less widely studied species. Research on highly social species still greatly outnumbers that on less social animals; however, studies on carnivores such as cats and bears are growing in number (Vonk \& Leete, 2017). This special issue is representative of the field in that the majority of studies on tool use and causality are conducted with primates (Bernstein-Kurtycz et al., 2020; DeLong \& Burnett, 2020; Jordan et al., 2020; Kersken et al., 2020) and a select group of birds - the corvids (Amodio et al., 2020; Taylor, 2020). But Barrett and Benson-Amram (2020) demonstrate that methods popularized by studies of primates (e.g., DeLong \& Burnett, 2020) can be applied to less typical study subjects, such as elephants, as well.

Scientists have been able to study a larger number of species in part out of necessity as there are fewer opportunities for prolonged studies of laboratory animals that characterized work in the last century. Research has moved out of the lab and into other settings, allowing access to previously understudied species, such as carnivores (Vonk \& Leete, 2017) and pangolins (DiPaola et al., 2020). This movement from the lab to zoological facilities and field sites has removed some of the capacity for control that was evidenced in work like Povinelli's, but it will open the door to understanding the diversity of species and the perceptual and cognitive processes that characterize and enable them to solve the challenges relevant to their own environmental niches. Bernstein-Kurtycz et al. (2020) provide one example of a study designed to capture natural chimpanzee behavior in a social context despite occurring in a zoological rather than a natural setting. Fragaszy and Mangalam (2020) propose a perceptioncentered ecological approach as an alternative to what they deem the "Cartesian" approach that dominated cognitive studies at the time of Povinelli's studies. Further attempts to design studies that ask how animals solve problems they are already solving rather than presenting them with tasks that fail to shed light on their evolved capacities is the way to understand the evolutionary pressures selecting for diverse cognitive traits. In conclusion, comparative researchers appear to have recognized necessary changes that will facilitate a greater understanding of nonhuman minds, but much work is needed to enact these changes.

\section{References}

Amodio, P., Boeckle, M., Jelbert, S.A., Ostojić, L., \& Clayton, N.S. (2020). How flexible is tool use in Eurasian jays (Garrulus glandarius)? Animal Behavior and Cognition, 7(3), 270-287. https://doi.org/10.26451/abc.07.03.02.2020

Barrett, L. P., \& Benson-Amram, S. (2020). Can Asian elephants use water as a tool in the floating object task? Animal Behavior and Cognition, 7(3), 310-326. https://doi.org/10.26451/abc.07.03.04.2020

Beran, M. J. (2018). Replication and pre-registration in comparative psychology. International Journal of Comparative Psychology, 31. https://escholarship.org/uc/item/59f4z2nd

Beran, M. J. (2020). Editorial: The value and status of replications in animal behavior and cognition research. Animal Behavior and Cognition, 7(1), i-iii. https://doi.org/10.26451/abc.07.01.01.2020

Bernstein-Kurtycz, L. M., Hopper, L. M., Ross, S. R., \& Tennie, C. (2020). Zoo-housed chimpanzees can spontaneously use tool sets but perseverate on previously successful tool-use methods. Animal Behavior and Cognition, 7(3), 288-309. https://doi.org/10.26451/abc.07.03.03.2020

Boesch, C. (2020a). Listening to the appeal from the wild. Animal Behavior and Cognition, 7(2), 257-263. https://doi.org/10.26451/abc.07.02.15.2020 
Boesch, C. (2020b). Mothers, environment, and ontogeny affect cognition. Animal Behavior and Cognition, 7(3), 474-489. https://doi.org/10.26451/abc.07.03.13.2020

DeLong, C. M., \& Burnett, C. (2020). Bornean orangutans (Pongo pygmaeus pygmaeus) use water as a tool in the floating object task. Animal Behavior and Cognition, 7(3), 327-342. https://doi.org/10.26451/abc.07.03.05.2020

de Waal, Frans B. M., \& Ferrari, P. F. (2010). Towards a bottom-up perspective on animal and human cognition. Trends in Cognitive Sciences, 14(5), 201-207. http://10.1016/j.tics.2010.03.003

DiPaola, J.D., Yindee, M., \& Plotnik, J.M. (2020). Investigating the use of sensory information to detect and track prey by the Sunda pangolin (Manis javanica) with conservation in mind. Scientific Reports, 10, 9787 http://doi.org/10.1038/s41598-020-65898-x

Eaton, T., Hutton, R., Leete, J., Lieb, J., Robeson, A., \& Vonk, J. (2018). Bottoms-up: Rejecting top-down humancentered approaches in comparative psychology. International Journal of Comparative Psychology, 31. https://escholarship.org/uc/item/11t5q9wt

Farrar, B. G., Boeckle, M., \& Clayton, N. S. (2020b). Replications in comparative cognition: What should we expect and how can we improve? Animal Behavior and Cognition, 7(1), 1-22. https://doi.org/10.26451/abc.07.01.02.2020

Farrar,' B. G., Altschul, D. M., Fischer, J., van der Mescht, J., Placì, S., Troisi, C. A., Vernouillet, A., Clayton, N. S., \& Ostojić, L. (2020). Trialling meta-research in comparative cognition: Claims and statistical inference in animal physical cognition. Animal Behavior and Cognition, 7(3), 419-444. https://doi.org/10.26451/abc.07.03.09.2020

Fragaszy, D. M., \& Mangalam, M. (2020). Folks physics in the twenty-first century: Understanding tooling as embodied. Animal Behavior and Cognition, 7(3), 457-473. https://doi.org/10.26451/abc.07.03.12.2020.

Heyes, C. M. (1998). Theory of mind in nonhuman primates. Behavioral and Brain Sciences, 21(1), 101-134. http://dx.doi./10.1017/S0140525X98000703

Horschler, D.J., MacLean, E.L. \& Santos, L.R. (2020). Do non-human primates really represent others' beliefs? Trends in Cognitive Sciences, 24, 594-605. https://doi.org/10.1016/j.tics.2020.05.009

Jordan, E. J., Townrow, L. A. J., Wright, C. I., \& Seed, A. M. (2020). Understanding solidity: Investigating knowledge of a functional object property in brown capuchin monkeys (Sapajus apella) and common squirrel monkeys (Saimiri sciureus). Animal Behavior and Cognition, 7(3), 365-391. https://doi.org/10.26451/abc.07.03.07.2020

Kersken, V., Zhang, D., Gomez, J-C., Seed, A., \& Ball, D. (2020). Capuchin monkeys individuate objects based on spatio-temporal and property/kind information: Evidence from looking and reaching measures. Animal Behavior and Cognition, 7(3), 343-364. https://doi.org/10.26451/abc.07.03.06.2020

Krupenye, C., \& Call, J. (2019). Theory of mind in animals: Current and future directions. WIREs Cognitive Science, 10:e1503. https://do1.org/10.1002/wcs.1503

Lazareva, O. F., Shimizu, T., \& Wasserman, E.A. (2012). How animals see the world: Comparative behavior, biology, and evolution of vision. Oxford University Press. http://dx.doi./10.1093/acprof:oso/9780195334654.

ManyPrimates, Altschul, D., Beran, M. J., Bohn, M., Caspar, K., Fichtel, C., Forsterling, M., Grebe, N.M., Hernandez-Aguilar, A., Chai Kwok, S., Llorente, M., Motes-Rodrigo, A., Proctor, D., Sânchez-Amaro, A., Simpson, E.A., Szabelska, A., Taylor, D., van der Mescht, J., Völter, C.J. \& Watzek, J. (2019a). Collaborative open science as a way to reproducibility and new insights in primate cognition research. PsyArXiv https://dx.doi.org/10.31234/osf.io/8w7zd

ManyPrimates, Altschul, D. M., Beran, M. J., Bohn, M., Call, J., DeTroy, S., Duguid, S.J., Egelkamp, C.L., Fichtel, C., Fischer, J., Flessert, M., Hanus, D., Haun, D.B.M., Haux, L.M., Hernandez-Aguilar, A., Herrmann, E., Hopper, L.M., Joly, M., Kano, F., Keupp, S., Melis, A.P., Motes Rodrigo, A., ... Watzek, J. (2019b). Establishing an infrastructure for collaboration in primate cognition research. PLOS ONE, 14, e0223675. http://dx.doi.org/10.1371/journal.pone.0223675

Penn, D. C., Holyoak, K. J., \& Povinelli, D. J. (2008). Darwin's mistake: Explaining the discontinuity between human and nonhuman minds. Behavioral and Brain Sciences, 31(2), 109-130. https://dx.doi./10.1017/S0140525X08003543

Povinelli, D.J. (2000). Folk physics for apes: The chimpanzee's theory of how the world works. Oxford University Press.

Povinelli, D. J., \& Dunphy-Lelii, S. (2001). Do chimpanzees seek explanations? Preliminary comparative investigations. Canadian Journal of Experimental Psychology/Revue Canadienne De Psychologie Expérimentale, 55(2), 185-193. https://dx.doi.org.10.1037/h0087365 
Povinelli, D. J, Glorioso, G.C., Kuznar, S.L. \& Pavlic, M. (2019). Dual systems for all: Higher-order, role-based relational reasoning as a uniquely derived feature of human cognition. Behavioral and Brain Sciences, 42, e271. https://doi.org/10.1017/S0140525X19000451

Povinelli, D. J., \& Henley, T. (2020). More rope tricks reveal why more task variants will never lead to strong inferences about higher-order causal reasoning in chimpanzees. Animal Behavior and Cognition, 7(3), 392418. https://doi.org/10.26451/abc. 07.03 .08 .2020

Povinelli, D. J., \& Vonk, J. (2003). Chimpanzee minds: Suspiciously human? Trends in Cognitive Science, 7, 157160. https://doi.org/10.1016/S1364-6613(03)00053-6

Shubiger, M. N., Fichtel, C., \& Burkart, J. M. (in press). Validity of cognitive tests for nonhuman animals: Pitfalls and prospects. Frontiers in Psychology. https://doi:10.3389/fpsyg.2020.01835

Stevens, J. R. (2017). Replicability and reproducibility in comparative psychology. Frontiers in Psychology, 8, 862. https://doi.org/10.3389/fpsyg.2017.00862

Taylor, A. H. (2020). Folk physics for crows? Animal Behavior and Cognition, 7(3), 452-456. https://doi.org/10.26451/abc.07.03.10.2020

Taylor, A. H. (2014). Corvid cognition. Wiley Interdisciplinary Reviews Cognitive Science, 5, 361-372. http://dx.doi: $10.1002 /$ wcs. 1286

Tomasello, M., Call, J., \& Hare, B. (2003). Chimpanzees understand psychological states - the question is which ones and to what extent. Trends in Cognitive Sciences, 7(4), 153-156. http://dx.doi./10.1016/S1364$\underline{6613(03) 00035-4}$

van 't Veer, A. E., \& Giner-Sorolla, R. (2016). Pre-registration in social psychology-A discussion and suggested template. Journal of Experimental Social Psychology, 67, 2-12. http://dx.doi./10.1016/j.jesp.2016.03.004

Völter, C.J., Lambert, M.L., \& Huber, L. (2020). Do nonhumans seek explanations? Animal Behavior and Cognition, 7(3), 445-451. https://doi.org/10.26451/abc.07.03.10.2020

Vonk, J. (2002). Can orangutans and gorillas acquire concepts for social relationships? International Journal of Comparative Psychology, 15, 257-277.

Vonk, J. (2003). Gorilla (Gorilla gorilla gorilla) and Orangutan (Pongo abelii) understanding of first and second order relations. Animal Cognition, 6(2), 77-86. https://DOI: 10.1007/s10071-003-0159-x

Vonk, J. (2013). Matching based on biological categories in orangutans (Pongo abelii) and a gorilla (Gorilla gorilla gorilla). PeerJ. 1, e158 https://doi.org/10.7717/peerj.158

Vonk, J., \& Eaton, T. (2018). Personality in nonhuman animals: Comparative perspectives and applications. In V. Zeigler-Hill \& T. Shackelford (Eds.), The Sage handbook of personality and individual differences (pp. 2351). Sage Publishers.

Vonk, J., \&, Edge, J. (in press). False dichotomies in the study of animal cognition. In S. Della Sala (Ed.), The Encyclopedia of Behavioural Neuroscience 2e. Elsevier.

Vonk, J., \& Hamilton, J. (2014). Orangutans (Pongo abelii) and a gorilla (Gorilla gorilla gorilla) match features in familiar and unfamiliar individuals. Animal Cognition, 17(5), 1089-1105. https://doi.org/10.1007/s10071$\underline{014-0741-4}$

Vonk, J., \& Krause, M. A. (2018). Editorial: Announcing preregistered reports. Animal Behavior and Cognition, 5(2), i-ii. https://doi.org/10.26451/abc.05.02.00.2018

Vonk, J., \& Leete, J. (2017). Carnivore concepts: Categorization in carnivores "bears" further study. International Journal of Comparative Psychology, 30. http://escholarship.org/uc/item/61363164

Vonk, J., \& MacDonald, S.E. (2002). Natural concept formation in a juvenile gorilla (Gorilla gorilla gorilla) at 3 levels of abstraction. Journal of the Experimental Analysis of Behavior, 78(3), 315-332. https://doi.org/10.1901/jeab.2002.78-315

Vonk, J., \& MacDonald, S.E. (2004). Levels of abstraction in orangutan (Pongo abelii) categorization. Journal of Comparative Psychology, 118(1), 3-13. https://doi.org/10.1037/0735-7036.118.1.3

Vonk, J., \& Povinelli, D.J. (2006). Similarity and difference in the conceptual systems of primates: The Unobservability hypothesis. In E. Wasserman \& T. Zentall (Eds.), Comparative cognition: Experimental explorations of animal intelligence (pp. 363-387). Oxford University Press.

Webster, W.M., \& Rutz, C. (2020). How STRANGE are your study animals? Nature, 582, 337-340. https://doi:10.1038/d41586-020-01751-5 